\title{
A morte do livro? Notas sobre a história da leitura na era da dispersão
}

\author{
La muerte del libro? Notas sobre la historia de la lectura en la era de la dispersión
}

The death of the book? Notes on Reading History in the era of dispersion

\author{
Joaci Pereira FURTADo \\ Departamento de Ciência da Informação, Instituto de Arte e Comunicação Social, Universidade Federal Fluminense, \\ Rua Lara Vilela, 126 - São Domingos - 24210-590 Niterói RJ - Brasil, joacifurtado@id.uff.br
}

\begin{abstract}
Resumen
¿Cómo se puede escribir la historia de esta práctica la lectura- que, hasta el final del siglo XX, se entrelaza con las formas materiales que la definían, como el libro, los periódicos o las revistas? En la era de los medios digitales y lectores virtuales, ¿cuáles son los vestigios que quedarán como testimonio de la lectura? Lejos de responder a estas preguntas, en estas notas se relatan algunas de las preocupaciones del autor sobre el tema y se apuntan algunas hipótesis metodológicas.
\end{abstract}

Palabras clave: Lectura. Hipercomunicación. Lectores digitales. Crisis.

A Eduardo Murguia (1954-2015), porque talvez a morte seja incompreensível.

\section{I}

O horror daquela mãe ao descobrir a filha que tinha: tendo prometido emprestar as Reinações de Narizinho a uma colega, ela obrigava a coitada vir diariamente à sua porta, durante semanas ou meses a fio, para fazê-la ouvir que voltasse no dia seguinte, pois o livro estava com outra pessoa. O volume, porém, jamais saíra de casa e sua perversa proprietária nunca o lera. $\mathrm{O}$ prazer da garota estava em testar os limites da obstinação da colega - ou a capacidade desta de suportar o sofrimento que gratuitamente lhe era impingido. Ao estarrecimento, porém, segue-se a redenção. Não da filha, provavelmente, mas talvez da mãe e, com certeza, da protagonista, que narra a história: a intervenção providencial da boa senhora lhe concedeu o empréstimo da obra "'por quanto tempo quiser'. Entendem? Valia mais do que me dar o livro: "pelo tempo que eu quisesse' é tudo o que uma pessoa, grande ou pequena, pode ter a ousadia de querer". A história termina com o livro aberto no colo da narradora, que languidamente se estende na rede sem tocá-lo: "Não era mais uma menina com um livro: era uma mulher com o seu amante" (Lispector, 1998, p. 11-2).

\begin{abstract}
What is the point of reading in the contemporary world? How does one write the history of this practice, reading, that, until the end of the twentieth century, was intertwined with the very material forms that defined it, such as the book, newspaper and magazine? In the age of digital media and virtual readership, what are the vestiges of reading that will be left as its testimony? Far from answering these questions, these notes bring together some concerns and point to some methodological hypotheses.
\end{abstract}

Keywords: Reading. Hyper-communication. Virtual readership. Crisis.

Foi necessária certa realidade para que essa fiç̧ão, configurada na linguagem e na sensibilidade estética que a caracterizam, se produzisse. Ou alguém consegue imaginar o conto "Felicidade clandestina" escrito com semelhante enredo na Idade Média francesa - ou mesmo no Oitocentos brasileiro? À medida que avança o século XXI ele certamente deve soar cada vez mais estranho - ainda que, do ponto de vista histórico, a obra seja bastante recente. Como uma préadolescente, em plenos anos 2000 , poderia se mobilizar a tal ponto por folhas de papel dobradas e juntadas, com letras impressas nas quatro faces, formando cadernos costurados que, por sua vez, são recobertos por uma capa igualmente de papel e com letras e, na maioria dos casos, imagens também impressas? Como alguém pode sofrer tanto apenas porque deseja ler... um livro? Um livro ao qual agora é preciso acrescentar o adjetivo "impresso", condição para o estranhamento que vai se configurando nestes tempos. É bem possível que ainda haja garotas com especial predileção pelo formato codex, essa invenção latina do século I d. C. fadada a conviver com os suportes eletrônicos de leitura quando não a ser superada por eles. Mas se o conto de Clarice Lispector fosse reescrito por um(a) jovem ficcionista de 2016, é bastante plausível que apenas o fetiche de bibliófila justificasse 
a obsessão da narradora pelo codex de um livro cujo conteúdo está disponível para compra em formato digital - ou gratuitamente num site, pirateado. No enredo original da narrativa, a única via de acesso à obra de Monteiro Lobato era o formato impresso, tal como inventado na Europa do século $X V$. Para uma pré-adolescente de família modesta, no Recife do século $X X$, as únicas alternativas honestas para ter o livro nas mãos eram a biblioteca pública ou o empréstimo. Se, pois, a leitura é uma prática social, como seria, na sociedade contemporânea, a relação com o livro e, mais especificamente, com os modos de ler?

Não há evidências, por enquanto, de que o livro impresso esteja irrecorrivelmente sentenciado ao desaparecimento, embora seja pertinente supor que, cada vez mais (até que ponto, porém, não se sabe, a não ser em exercícios estúpidos de futurologia), ele conviverá com suas versões em suportes digitais. Seja como for, é ilusório negar que estes e a internet causaram, ao menos desde os anos 1990, "uma revolução nas estruturas do suporte material do escrito assim como nas maneiras de ler" (Chartier, 1998, p. 13). Anunciada, negada ou analisada por uma bibliografia proporcionalmente considerável (1), se levarmos em conta o estado tenro da questão, a "morte do livro" inscreve-se numa tópica bastante conhecida - em que brilha, ao menos no âmbito do que interessa aqui, o célebre ensaio de Roland Barthes, "A morte do autor" (Barthes, 1987). Os termos da questão, entretanto, me parecem equivocados. Ou carentes de certa modulação, pois agora a palavra "livro" nomeia também um conteúdo e não apenas uma forma - enquanto "biblioteca" designa cada vez mais uma função, e não somente um espaço. Se cabe falar em "morte" ou "fim", estes dois termos se aplicam muito mais à hegemonia do codex, tecnologia que, com ajustes e refinamentos, permaneceu basicamente a mesma durante dois mil anos. $\mathrm{O}$ livro, como sinônimo de um conteúdo escrito, continua vigoroso, mas agora disperso em outras formas que determinam ou reconfiguram sua leitura. Com a fotocópia, o e-book, o PDF e a internet, chamamos de "livro" as partes ou a íntegra de textos digitalizados que lemos em telas ou em folhas avulsas. Mas especialmente os suportes eletrônicos conferiram uma ubiquidade inaudita à palavra escrita e estenderam a autonomia do leitor a limites antes inimagináveis, ao ponto de ele poder ser também coautor do que lê (Fischer, 2006, p. 295-5). Mais que isso, agora o livro é pensável numa interação multimídia improvável até bem pouco tempo, não só mobilizando simultaneamente som e imagem em movimento (Chartier, 1998, p. 72-3), mas realizando na tela, por meio de hiperlinks, a labiríntica biblioteca de
Babel imaginada por Jorge Luis Borges (1999, p. 516-23).

Todo um universo de gestos, posturas corporais, comportamentos, valores e usos acumulados ou perdidos ao longo de quase seiscentos anos de convívio com o livro impresso certamente não farão o menor sentido numa eventual hegemonia do e-book. A iconografia em que figura o manuseio do codex testemunha a longa história dessa cultura mesmo antes do progressivo barateamento - e, portanto, da paulatina "popularização" - do objeto propiciado pelo surgimento da indústria editorial do livro, na metade do século $X V$ europeu. O célebre fragmento restante do retábulo Sacra conversação, por exemplo, em que aparece Maria Madalena lendo, pintado por Rogier van der Weyden entre 1435 e 1438, encena elementos dessa cultura na compenetração da leitora, reverentemente curvada sobre o volume aberto encima de um suporte forrado que repousa sobre seu colo.

Leitura silenciosa - algo raro, ainda naqueles tempos - mas não íntima, pois feita na presença ostensiva e provavelmente censória ou no mínimo sempre dissuasória de outros olhos (Fischer, 2006, p. 213-4), no contexto de uma "conversação". A leitura na privacidade do lar, silenciosa, mas não vigiada, será uma invenção burguesa a se disseminar pelo mundo, até chegar a certa rede de dormir imaginada no Recife. Madalena lê silenciosamente em público, mas não se dispersa, como se vê. A dispersão da leitura e o leitor disperso, se não são invenções recentes, foram infinitamente potencializados e multiplicados pelos suportes digitais, neste começo do século XXI.

Dessa secular cultura do livro impresso, o que resta das práticas de sua leitura na paisagem da privacidade e do espaço público contemporâneos? É possível elencar alguns signos, usos e posturas ainda bastante vigorosos. Ele caracteriza - embora cada vez menos - o estudante e o professor, é inseparável do hare krishna e do fiel evangélico, é carregado solenemente em rituais católicos, pesa na mesa do juiz e do gramático. A ele são dedicados espaços públicos próprios, às vezes monumentais, às vezes modernizados - neste caso, tentando se ressignificar num contexto em que o paradigma alexandrino parece definitivamente superado (Baratin, 2000, p. 227-33) e em que o acesso à informação pode se dar vitualmente de qualquer ponto do planeta. Comercializado, para ele são desenvolvidas lojas sofisticadas, que chegam a emular o ambiente da leitura em casa. Mas o livro impresso também pode ser doado, presenteado, emprestado - e nunca devolvido -, esquecido, 
abandonado, herdado, roubado, revendido, compartilhado, copiado à mão ou mecanicamente. $\mathrm{Na}$ intimidade, acalenta o sono e o imaginário de crianças, preenche o ócio de idosos, convalescentes e presidiários, jaz decorativamente sobre o tampo de coffee tables ou displicentemente sobre criados-mudos (ou sob a cama), abarrota estantes, acumula-se em pilhas empoeiradas pelos cantos da casa, envelhece e mofa sobre guardaroupas ou em porões e caixas, é riscado e anotado pelo pesquisador ou pelo leitor apaixonado pelo poema, guarda cartões postais, bilhetes, dinheiro, recortes de jornal, bula de remédio, o título de eleitor, a marca de uma lágrima. Com dimensões, pesos, cores, texturas, materiais e cheiros diferentes, é universalmente identificável. No imaginário coletivo, é tido como fonte ou signo de saber - quando não de sabedoria - e está inseparavelmente associado a certa noção de "cultura", mesmo entre aqueles que, apesar de alfabetizados, não lhe reservam sequer algumas horas por mês ou pela vida toda (2).

Os suportes eletrônicos, porém, sempre multifuncionais, aboliram a máxima de Marshall McLuhan de que "o meio é a mensagem", prestando-se à uma infinidade de usos inclusive simultâneos que eliminam a maioria (se não todas) das situações ou significações arroladas acima. Junto com o jornal, a revista e a carta, agora o livro pode ser lido na mesma tela do aparelho em que vemos filmes, ouvimos música, fotografamos, filmamos, escrevemos e falamos - numa fragmentação da atenção também sem precedentes, que ao mesmo tempo sacia e gera leitores ansiosamente divididos, prorrogando ou espelhando nas práticas de leitura a descorporificação da experiência humana, no âmbito daquilo que entendemos por "cultura" em sentido amplo, e, em sentido estrito, a constituição do leitor sobretudo como consumidor disperso, ubíquo e insone.

\section{II}

Se não há mundo da leitura sem leitura do mundo (Lajolo, 1993, p. 7), ou, em outras palavras, se "A leitura não é uma atividade isolada: ela encontra - ou deixa de encontrar - o seu lugar em um conjunto de atividades dotadas de sentido" (Petit, 2013, p. 104), ao fazer uma história dessa prática no século XXI talvez seja pertinente pensar as relações entre o ato de ler e a "descorporificação da experiência humana", de que fala Hans Ulrich Gumbrecht em Nosso amplo presente (2015, p. 121-2). No retrato pintado por Van der Weyden, a leitora está integralmente entregue ao livro - de corpo e alma, como se diz, e creio que aqui mui apropriadamente. Não há, em sua postura, uma atenção cindida: o volume ocupa o centro da cena, e é para ele que os olhos de Madalena, junto com os do observador, piedosamente convergem, é dele que seu corpo se constitui como suporte do suporte - ou como altar, trono, mesa ou até mesmo leito. Semelhante configuração, retoricamente regrada e decodificável pelos contemporâneos da obra, faz sentido numa sociedade fundamentada no primado da tradição (presente em vários signos, desde o pote de unguento ou relicário no canto inferior direito, selando o caráter cristão da pintura, até a cor da túnica da personagem: o verde da esperança, uma das três virtudes teologais) e da crença no Incriado, cuja presença, sob os influxos da luz inata da Graça evidenciando a Revelação, espera apenas ser lida em suas perenes manifestações no mundo, exatamente como um livro ou como "o" livro: a Bíblia. O leitor do século XXI, herdeiro da dessacralização do codex que principiou no XVI (sem minimizar aqui inúmeras nuances e aclimatações ao longo desse tempo) e da emancipação intelectual iluminista irradiada pela Revolução Francesa, é laico, confiante na inovação e, na prática, materialista, mesmo quando se diz crente ou se porta como fanático. Não há como esperar dele aquela entrega absoluta à leitura representada na Sacra conversação, ou a qualquer outra prática cultural, se "as nossas ideias, a nossa imaginação e os nossos sonhos cotidianos estão cada vez menos no mesmo lugar que o nosso corpo" (Gumbrecht, 2015, p. 124).

Os novos dispositivos eletrônicos de comunicação, escreve Gumbrecht, inovam não por emular ou exceder "a performance possível de um humano", mas pela ubiquidade da informação - e, portanto, da leitura, podemos acrescentar. A contrapartida desse admirável mundo novo prometido ou na perene iminência de realizar-se plenamente pela hipercomunicação está na "disponibilidade infinita": "queiramos ou não, é verdade que nós, isto é, os que usam os caixas eletrônicos e as telas digitais, se tornam mais acessíveis" (Gumbrecht, 2015, p. 115). O leitor contemporâneo pode acessar virtualmente "tudo" - ou a ilusão dessa totalidade. Mas pode ser igualmente acessado. Não apenas por um onipresente panóptico orwelliano, capaz de investigar hábitos de consumo e estilos de vida, apropriando-se desses dados para oferecer ou induzir o internauta com menor ou maior sutileza - à compra de produtos e serviços (Crary, 2014, p. 57), mas principalmente por estímulos permanentes de vária natureza, quase sempre de recorrente apelo narcísico e consumista, dispersando ou fragmentando sua atenção - ou, numa perspectiva bem menos otimista, submetendo-a "à diminuição das capacidades mentais e perceptivas em vez de sua expansão e modulação" (Crary, 2014, p. 43) - em duas ou mais personas simultâneas até 
bem pouco tempo (ao menos na maioria das combinações) incompatíveis ou excludentes num mesmo indivíduo: leitor, ouvinte, espectador, redator, editor, cliente, torcedor, fiel, cidadão, fotógrafo, videomaker, repórter, DJ, militante, mão de obra, voyeur... O homem solitário com quem cruzamos no espaço público, e que à primeira vista parece falar sozinho enquanto caminha, pode estar aludindo com a amante, por meio de discreto dispositivo de comunicação, "a momentos de intensidade erótica que recordam da noite anterior e que anseiam no futuro", compartilhando uma "bolha de privacidade estática" em meio ao ambiente formal e austero das relações de negócio que se dão em público (Gumbrechet, 2015, p. 121). Ou pode ser que ele apenas discute a lista de compras do supermercado com a esposa. Essa simultaneidade - cujas combinatórias tendem ao infinito -, ao mesmo tempo causa e efeito da potencialização de múltiplos estímulos, é a condição para a gênese do Homo vigiliis - o homem que nunca dorme - no terceiro milênio, colonizando o vazio cada vez mais largo de sua insônia - ou de sua angústia existencial? - com "necessidades ininterruptas, sempre encorajadas e nunca aplacadas" (Crary, 2014, p. 19). Vinte quatro horas por dia, sete dias por semana, o Homo vigiliis se expõe a "solicitações e atrações" que incapacitam "a visão, por meio de processos de homogeneização, redundância e aceleração" (Crary, 2014, p. 43). Se para a leitura - ou certa leitura "crítica", filha do iluminismo -, que é um modo de ver, antes demandava-se alteridade, espanto e lentidão, o que há de ser do ato de ler no contexto obnubilado, reiterativo e ansioso da hipercomunicação de agora? Como compreendê-lo, capturá-lo, percebê-lo em suas radicais dispersão e volatilidade? Que sentido, enfim, terá hoje a memória da leitura, se as "mídias digitais realizam o projeto moderno de produzir a simultaneidade instantânea, aqui e agora, ao mesmo tempo ausente, de todas as temporalidades do tempo" (Hansen, 2013, p. 21)?

\section{III}

A história das práticas de leitura em nossa contemporaneidade impõe, pois, questões metodológicas que seria pretencioso exaurir aqui, até porque não parece que estejam claras - ao menos para mim (e expor semelhante incerteza é o principal objetivo destas notas, na esperança de buscar a sempre enriquecedora interlocução). Mas é possível apontar algumas hipóteses de reflexão a respeito. A começar pela biblioteca. Se ela - com longa história de descaso no Brasil, onde nunca chegou, de fato, a ser "popular", e provavelmente nunca o será - esvaziou-se como lugar preferencial do livro, qual será sua função no século $X X I$ ? Uma resposta recente está sendo tentada, creio, na Biblioteca de São Paulo, iniciativa do governo estadual. Localizada no Parque da Juventude, na zona norte paulistana, em terreno onde funcionava a demolida penitenciária do Carandiru e que agora abriga também quadras de esportes, espaços para shows e áreas verdes, seu acervo prioriza o público infantil e juvenil, incluindo best-sellers. O que talvez seja mais significativo, porém, é o propósito explícito inscrito em seu projeto arquitetônico, resumido nestas palavras pelo então secretário estadual da Cultura, João Sayad: "A ideia é que ela pareça uma megastore pública. [...] Ela deve ter tudo aquilo que essas lojas oferecem, mas estará aberta para atender a todos" (Revista da Folha, 2010). Sobretudo no design dos móveis e em sua arquitetura interior, evidencia-se, nessa biblioteca, a emulação do ambiente intimista que as livrarias procuram proporcionar - por sua vez, propiciando um clima de intimidade doméstica. Ou seja, e salvo engano, trata-se de tornar o espaço público parecido com o privado - ou, antes, de fundir em um a natureza de três: a biblioteca pública, a megaloja de livros e o lar -.

Essa (con)fusão entre público e privado, agora arquitetonicamente "naturalizada", que efeitos poderia ter sobre a leitura? O ensino ou o estímulo institucionalizado do ato de ler se dará, daqui para frente, apenas em dispersivos espaços públicos multifuncionais que ao mesmo tempo pareçam biblioteca, livraria e lar? Ou ainda, que concepção de leitor e leitura se materializa nessa arquitetura? Para que corpo ela foi pensada? Para que gestos? Em nome de que valores?

A materialidade da edificação, do acervo e do mobiliário com certeza pode oferecer algumas respostas. Os usuários também, que em sua prática efetivam, contradizem, superam, negam, refratam, multiplicam, reinventam essa arquitetura. Como intérpretes do que leem, porém, onde deixam seus registros? Há sempre o recurso da entrevista qualitativa, se não estamos preocupados com quantidade, ou dos indícios estatísticos para análise de tendências gerais (frequência, faixa etária, escolaridade, sexo, renda etc.).

Mas erguendo a vista para além de um caso específico, quais os registros das práticas de leitura na era digital que o historiador poderia buscar? Os próprios dispositivos de leitura do e-book permitem que o fornecedor da obra rastreie até que página o livro foi "aberto" pelo consumidor: a rede de lojas Kobo, a pedido da colunista Raquel Cozer, do jornal Folha de S. Paulo, verificou que, em $2014,49,1 \%$ dos fãs brasileiros de $A$ culpa é das estrelas, de John Green, não concluiu a leitura do livro em sua versão eletrônica. Esse percentual 
sobe para $58,3 \%$ quando se trata de Cinquenta tons de cinza, de E. L. James (Cozer, 2015). São números eloquentes sobre o comportamento do leitor contemporâneo em relação a best-sellers vinculados a outra indústria, a do cinema, abrindo vasto campo de reflexão sobre as inseparáveis interações mercadológicas entre as mídias (livro, cinema, televisão, internet), dentro daquilo que chamamos de "indústria cultural".

Outro meio de perscrutarmos o leitor do século XXI são os comentários que ele posta em sites de livrarias ou dos jornais e revistas - ainda que muitos possam ser fraudulentos, decorrendo de ações estratégicas de marketing editorial. Pela internet grassam blogs e vlogs dedicados a livros - alguns bastante influentes -, e talvez eles sejam as fontes mais parecidas com o leitor de hoje, em sua maioria ostentando textos e vídeos entrecortados, dispersos, superficiais, vertiginosamente agitados e pateticamente infantilizados sobre obras de grande vendagem ou mesmo canônicas.

Enquanto nas redes sociais organizam-se comunidades de leitores diversos em torno de títulos, autores ou temas, com fóruns de debate, questões legais de privacidade dificultam o acesso à troca de e-mails entre editoras, autores e leitores - mas essa correspondência seria preciosíssima para uma história da leitura em nossa contemporaneidade, assim como os dados de vendas das próprias casas publicadoras (alguns, gerais, estão disponíveis virtualmente por meio de relatórios anuais de sindicatos de editores).

Os dispositivos de leitura dos e-books permitem intervenções do leitor, incluindo anotações - num sucedâneo eletrônico das antigas marginálias que faziam a alegria dos historiadores da leitura, ávidos por sondar como esta se efetivava aos oIhos até ou sobretudo do leitor mais anônimo. Se-ria possível resgatar essas anotações eletrôni-cas?

A era digital gera, numa proporção infinitamente superior, sua própria documentação para a história da leitura. Mas são documentos de outra natureza, bastante diversa daquela escrita sobre o papel, fruto de relação também diferente com a escrita - e, portanto, com a leitura. Mais que diferente, radicalmente outra:

Não sei se os meios digitais permitem hierarquizar o valor da informação, como ainda fazemos opondo literatura séria a literatura kitsch, ou se a própria literatura deles implica justamente a equalização de todos os valores. [...] De todo modo, as mídias digitais também alteram as condições da crítica, principalmente porque põem em crise a noção burguesa e romântica do autor como individualidade que tem a posse e a propriedade do texto original que produz; desierarquizam o valor estético dos textos e produzem um público espantosamente maior, incontável, ao mesmo tempo anônimo, disperso e fragmentado, que agora pode ter acesso a milhões de textos digitalizados e, quem sabe, lê-los. Mas como são lidos? E o que se faz com eles? (Hansen, 2013, p. 21-2).

Por isso talvez essa história careça de uma metodologia mais atenta às suas especificidades para não incorrer em anacronismos ou impressões equivocadas. Não há dúvida de que a leitura e o livro, tal qual idealizados no referido retrato de Madalena lendo, e até algumas décadas atrás não de todo estranhos a nós, estão definitivamente mortos. Resta compreender, afinal, o que nasceu em seu lugar.

\section{Notas}

(1) O exemplo mais célebre talvez seja Não contem com o fim do livro, de Umberto Eco e Jean-Claude Carrière. Vale lembrar também o ensaio Achados e perdidos no ciberespaço, em A questão dos livros: passado, presente e futuro, de Robert Darnton (2010).

(2) Partes deste parágrafo e dos dois anteriores derivam de outro artigo meu (Furtado, 2016).

\section{Referências}

Baratin, Marc (2000). Da biblioteca à gramática: o paradigma da acumulação. // Baratin, Mark \& Jacob, Christian (dir.). O poder das bibliotecas: a memória dos livros no Ocidente. Trad. Marcela Mortara. Rio de Janeiro: Editora da UFRJ, 2000. 227-33.

Barthes, Roland (1987). La muerte del autor. // El susurro del lenguaje: más allá de la palabra y la escritura. Trad. C. F. Medrano. Barcelona: Paidós, 1987. 65-71.

Borges, Jorge Luis (1999). A biblioteca de Babel. // Obras completas. Trad. Carlos Nejar. $3^{a}$ reimp. São Paulo: Globo, 1999, v. 1, 516-23.

Chartier, Roger (1998). A aventura do livro do leitor ao navegador. Trad. Reginaldo Carmello Corrêa de Moraes. São Paulo: Editora Unesp, 1998.

Cozer, Raquel (2015). No meio do caminho. // Folha de S. Paulo, São Paulo, 13. mar. 2015, Ilustrada. http://www1.folha.uol.com.br/fsp/ilustrada/211745-nomeio-do-caminho.shtml.

Crary, Jonathan (2014). 24/7: capitalismo tardio e os fins do sono. Trad. Joaquim Toledo Jr. São Paulo: Cosac Naify, 2014.

Darnton, Robert (2010). Achados e perdidos no ciberespaço. // A questão dos livros: passado, presente e futuro. Trad. Daniel Pellizzari. São Paulo: Companhia das Letras, 2010, 76-82.

Eco, Umberto; Carrière, Jean-Claude (2010). Não contem com o fim do livro. Trad. André Telles. Rio de Janeiro: Record, 2010.

Fischer, Steven Roger (2006). História da leitura. Trad. Claudia Freire. São Paulo: Editora da Unesp, 2006.

Funrtado, Joaci Pereira (2016). A morte da biblioteca? O lugar do livro e do leitor na era da dispersão. // Visualidades. 13:2. ISSN 2317-6784. doi:http://dx.doi.org/10. 5216/vis.v13i2.40735.

Gumbrecht, Hans Ulrich (2015). Disponibilidade infinita: da hipercomunicação (e da terceira idade). // Nosso amplo presente: o tempo e a cultura contemporânea. Trad. Ana Isabel Soares. São Paulo: Editora Unesp, 2015. 113-29. 
Hansen, João Adolfo (2013). O que é um livro?. São Paulo: Sesc São Paulo, 2013.

Lajolo, Marisa (1993). Da leitura do mundo para ao mundo da leitura. São Paulo: Ática, 1993.

Lispector, Clarice (1998). Felicidade clandestina. // Felicidade clandestina. Rio de Janeiro: Rocco, 1998. 9-12.

Petit, Michèle (2013). Os jovens e a leitura: uma nova perspectiva. Trad. Celina Olga de Souza. 2. ed. São Paulo: Editora 34, 2013.
Revista da Folha (2010). Pavilhão das letras. São Paulo, 31 jan. 2010. http://www1.folha.uol.com.br/revista/rf31012 01005.htm.

Enviado: 2016-02-19. Segunda versión: 2016-05-14 Aceptado: 2016-06-09. 